Official Publication of the Indian Pharmacological Society

October 2007 Vol $39 \quad$ Issue 5

\section{Indexed / Listed in}

Science Citation Index, Journal Citation Report, Biological Abstracts/Biosis, Chemical Abstracts, EMBASE/Excerpta Medica, CAB Abstract, Global Health, Excerpta Medicinal and Aromatic Plants Abstracts, Health \& Wellness Research Center, Health Reference Center Academic, InfoTrac One File, Expanded Academic ASAP, NCI Current Contents, Indian Science Abstracts, IndMed, and Medind.

\section{Publication}

The journal is published six times in a year in the months of February, April, June, August, October and December.

\section{Copyright and Photo-copying}

No part of this publication may be reproduced or transmitted in any form or by any means, electronic or mechanical, including photocopy without permission in writing from the Chief Editor.

\section{Correspondence}

Enquiries should be addressed to the Chief Editor.

\section{Disclaimer}

The Chief Editor disclaims any responsibility for statements made and opinions expressed by authors or claims made by the advertisers.

\section{Disputes}

Readers, contributors, members and advertisers may approach the President, IPS, in case of disputes with the IJP.

The journal is printed on acid free paper

\section{IPS Members}

The issues are supplied for Rs. 5.00 to members in India. Members residing overseas can get the issues on payment of US\$ 25/ annum towards airmail charges.

\section{Missing Issues}

Claims for missing issues should be sent within 2 months of issue date.

\section{Published by}

Medknow Publications

A-109, Kanara Business Centre, Off Link Road, Ghatkopar (E), Mumbai - 400075,

India. Phone: 91-22-6649 1818/1816,

Fax: 91-22-6649 1817,

Web: www.medknow.com

\section{Websites}

www.ijp-online.com

www.journalonweb.com/ijp

www.bioline.org.br/ph

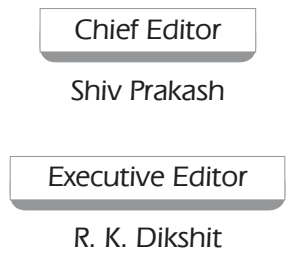

\begin{tabular}{|c|}
\hline Associate Editor \\
Varsha Patel
\end{tabular}

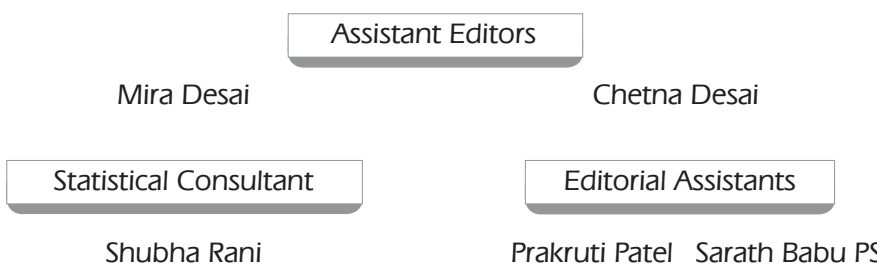

\begin{tabular}{ll}
\cline { 2 - 2 } & \multicolumn{1}{c}{ International Advisory Board } \\
\cline { 2 - 2 } Adithan C, India & Anil Gulati, USA \\
Bhaskar Jasti, USA & Diwan PV, India \\
Ding Jian, China & Gupta JB, India \\
Gambhir SS, India & Gupta YK, India \\
Jagadish G, USA & Lennard MS, UK \\
Manjeet Singh, India & Mario A. Gonzalez, USA \\
Mehendale HM, USA & Naidu MUR, India \\
Nanivadekar AS, India & Narayana DBA, India \\
Ozturk Y, Turkey & Pipasha Biswas, UK \\
Rao V.S.V. Vadlamudi, India & Uthai Suvanakoot, Thailand
\end{tabular}

Editorial Board

Arunabha Ray, Delhi

Dinesh Kumar, Hyderabad

Jagadeesh K, Davangere

Kulkarni SK, Chandigarh

Malik JK, Izatnagar

Mody SK, Sardar Krushinagar

Moulik SK, Delhi

Pundarikakshadu K, Ahmedabad

Rama Rao P, Chandigarh

Ramesh K. Goyal, Ahmedabad

Seshagiri Rao C, Hyderabad

Sushma Mengi, Mumbai

Thatte UM, Mumbai

G. Parthasarathy, Mysore
Bhupendra Singh Bhoop, Chandigarh

Flora SJS, Gwalior

Katiyar CK, Delhi

Madhu Dikshit, Lucknow

Mallikarjuna Rao C, Manipal

Mohanasudaram J, Chennai

Nilima Kshirsagar, Mumbai

Rajan Vedasiromani J, Kolkata

Ramkishan A, Ahmedabad

Roy BK, Ranchi

Shankarnarayana A, Coimbatore

Tripathi SK, Kolkata

Usharani P, Hyderabad

RS Bhatia, Ludhiana 


\section{Indian Journal of Pharmacology}

Official Publication of the Indian Pharmacological Society

October 2007 Vol 39 Issue 5

\section{CONTENTS}

\section{Editorial}

Irrational combinations: No consideration for patient safety: Shiv Prakash

\section{Review Article}

Bioequivalence: Issues and perspectives: Shubha Rani

\section{Research Papers}

Isolation, characterization and study of enhancing effects on nasal absorption of insulin in rat of the total saponin from Acanthophyllum squarrosum: S.A. Sajadi Tabassi, H. Hosseinzadeh, M. Ramezani, E. Moghimipour, S.A. Mohajeri

Pharmacological and biochemical evidence for the antidepressant effect of the herbal preparation Trans-01: Md. Shalam, S.M. Shantakumar, M. Laxmi Narasu

Effects of dexamethasone and betamethasone as COX-2 gene expression inhibitors on rigidity in a rat model of Parkinson's disease: Mehdi Shafiee Ardestani, Hassan Mehrab, Nourallah Sadeghzadeh

Activity of aqueous ethanol extract of Euphorbia prostrata ait on Shigella dysenteriae type 1-induced diarrhea in rats:

Kamgang René, Gonsu Kamga Hortense, Wafo Pascal, Mbungni N. Jean Alexis, Pouokam Ervice Vidal,

Fokam Tagne Michel Archange, Fonkoua Marie Christine

Antidiarrheal and antimicrobial activities of Stachytarpheta jamaicensis leaves: S. Sasidharan, L. Yoga Latha, Z. Zuraini, S. Suryani, S. Sangetha, L. Shirley

\section{Research Letters}

Positive inotropic and chronotropic effect of aloe gel on isolated rat heart: Pradeep Kumar, Manish Goyal, Sunita Tewari

Synergistic effect of cefixime and cloxacillin combination against common bacterial pathogens causing community acquired pneumonia: Astha Agarwal, N. Jain, A. Jain

In vitro cytotoxic and human recombinant caspase inhibitory effect of Annona reticulata leaves: Susanta Kumar Mondal, Nirup Bikash Mondal, Upal Kanti Mazumder

\section{Correspondence}

Counterfeit and substandard drugs: The need for an effective and stringent regulatory control in India and other developing countries: A. Sukhlecha

\section{Letter to the Editor}

Postgraduate education in medical pharmacology: A student's viewpoint: Varun Gupta

\footnotetext{
The copies of the journal to members of the association are sent by ordinary post. The editorial board, association or publisher will not be responsible for non-receipt of copies. If any of the members wish to receive the copies by registered post or courier, kindly contact the journal's / publisher's office. If a copy returns due to incomplete, incorrect or changed address of a member on two consecutive occasions, the names of such members will be deleted from the mailing list of the journal. Providing complete, correct and up-to-date address is the responsibility of the members. Copies are sent to subscribers and members directly from the publisher's address; it is illegal to acquire copies from any other source. If a copy is received for personal use as a member of the association/society, one cannot resale or give-away the copy for commercial or library use.
} 


\title{
Isolation, characterization and study of enhancing effects on nasal absorption of insulin in rat of the total saponin from Acanthophyllum squarrosum
}

\author{
S.A. Sajadi Tabassi, H. Hosseinzadeh*, M. Ramezani*, E. Moghimipour*, S.A. Mohajeri*
}

Pharmacological Research Center of Medicinal Plants and School of Pharmacy, *Pharmaceutical

Research Center, Mashhad University of Medical Sciences, $\mathrm{P} O$ Box 1365-91775, Mashhad, Iran

Received: 18.01 .2005

Revised: 28.02.2005

Accepted: 12.10 .2007

Correspondence to: Sajadi Tabassi

E-mail: s-sajjadi@mums.ac.ir

\begin{abstract}
O bjective: Isolation of the total saponins from Acanthophyllum squarrosum Boiss. and investigation of its surface activity, haemolytic effects on human erythrocytes, as well as enhancing potentials on intranasal insulin absorption in rat as compared to two other enhancers, i.e, Q uillaja total saponin (QTS) and sodium cholate (SC).

Materials and M ethods: The decrease in blood glucose levels in five fasting rats following nasal administration of regular insulin solutions in the presence or absence of enhancers was determined by glucometric strips and used as an indication of insulin absorption.

Results: The results showed that Acanthophyllum total saponin (ATS) decreased surface tension of water to about 50 dyne/cm and caused complete haemolysis of human RBCs at a concentration of $250 \mu \mathrm{g} / \mathrm{ml}$. Following the instillation of solutions containing insulin and different absorption enhancers into the right nostril of rats, the percentage decrease in initial blood glucose was as follows: $72.46 \%( \pm 2.39 \%)$ for ATS, $63.22 \%( \pm 11.06 \%)$ for QTS and $60.06 \%( \pm 14.93 \%)$ for SC. Percentage lowering of initial blood glucose concentrations against time showed that ATS exerts a stronger effect than the two other enhancers, although the difference was not statistically significant $(P>0.05)$.

Conclusion: ATS has a considerable absorption enhancing effect and can possibly be used to increase insulin bioavailability via the nasal route. However, the potential toxic effects of this saponin on nasal mucosa should be further evaluated.
\end{abstract}

KEY WORDS: Absorption enhancers, acanthophyllum, insulin, saponin
Saponins are a ubiquitous group of amorphous glycosides that are widely distributed in the higher plants. They dissolve in water to form colloidal solutions that foam upon shaking and can be distinguished from other glycosides by their surface active properties. ${ }^{11}$ Most saponins have shown haemolytic activity and are toxic to most cold-blooded animals. ${ }^{[2]}$

In view of the vital role of insulin and the daily need for injections (the only available dosage form of insulin) in type I diabetes patients, there is pressing need to identify other possible administration routes, e.g., the intranasal pathway; however, an answer to this problem has eluded pharmaceutical researchers over the recent decades. ${ }^{[3]}$ Studies which have been carried out on nasal drug delivery for systemic purposes in recent years have shown that the nasal route can be exploited for the systemic delivery of drugs such as small molecular weight polar drugs as well as peptides and proteins. ${ }^{[4]}$ Small lipophilic molecules are generally well absorbed through the nasal mucosa ${ }^{|4|}$ However, the same is not applicable for high molecular weight polypeptides such as insulin. To overcome the problem of poor nasal absorption of polypeptides and proteins, different strategies have been adopted, including the use of chemical absorption enhancers. ${ }^{[5,6]}$ Various substances have been studied for use as absorption enhancers of insulin through nasal mucosa, including bile salts; ${ }^{[7]}$ polyoxyethylene9-lauryl ether [laureth-9]; ${ }^{|3,8|}$ anionic surfactants, e.g, sodium lauryl sulfate (SLS) and potassium lauryl sulfate; ${ }^{[9]}$ l- $\alpha$-lysophosphatidyl choline, ${ }^{\mid 10]}$ chitosan $^{[11,12]}$ and Quillaja saponins. ${ }^{[13]}$ Pillion and coworkers studied the enhancing effects of Quillaja total saponin (QTS) and its derivatives on nasal and ocular delivery of insulin. ${ }^{[13]}$ However, no report was found in the literature regarding the absorption-enhancing effects of Acanthophyllum total saponin (ATS).

The aim of the present study was to isolate and characterize ATS and investigate its enhancing effects on intranasal insulin absorption in comparison with two other enhancers, i.e., QTS and SC.

\section{Materials and Methods}

\section{Chemicals}

Chemicals and their suppliers were as follows: QTS (Sigma, USA); sodium cholate (SC) (Merck, Germany); carboxy methyl cellulose (CMC) (Alborz Co. Iran); glucometer strips (Apex 
Biotechnology Corp. USA); regular insulin solution $100 \mathrm{IU} / \mathrm{ml}$ (NOVO, Denmark); heparin 5000 IU/ml (B. Braun Medicals S.A, Germany). All chemicals were of analytical grade and used as received.

\section{Extraction of saponin}

ATS was extracted from the roots of Acanthophyllum squarrusom using the method described earlier. ${ }^{[14]}$ Briefly, the roots were collected from around the city of Tabas, north of Yazd Province, Iran and identified by Fersdowsi University of Mashhad. Voucher samples were preserved for reference in the herbarium of the Department of Pharmacognosy, School of Pharmacy, Mashhad (Voucher no. 003-0119-1).

The roots of the plant were dried, powdered and defatted with petroleum ether in a Soxhlet. The air-dried powder was extracted with methanol and after evaporation yielded a syrupy brown residue. It was then extracted with water-saturated n-butanol. The residue was dissolved in the least amount of methanol and precipitated by the addition of five volumes of diethyl ether. After filtration, the residue was dissolved again in methanol and precipitated by adding diethyl ether twice. Finally, the total saponin was freeze-dried (Freeze Dryer 3, LABCONCO) and stored in an amber, air tight glass container at room temperature for further studies.

\section{Characterization of saponin}

High performance liquid chromatography (HPLC): HPLC fingerprint of the isolated ATS was taken (Waters $600 \mathrm{E}$, Waters Co, UK) with a Licrosphere $\mathrm{C}_{18}$ column $(5 \mu \mathrm{m}$, $125 \times 4 \mathrm{~mm}$ ). The samples were eluted with water: methanol: methyl cyanide at a flow rate of $1.0 \mathrm{ml} / \mathrm{min}$ and detected by a UV detector at the wavelength of $210 \mathrm{~nm}$.

Surface activity and critical micelle concentration $(\mathbf{c m c})$ : Surface activity of the aqueous solutions of saponin was determined using Wilhelmy plate apparatus (Model $\mathrm{K}_{12}$, Kruss Processor Tensiometer). Approximately, $20 \mathrm{ml}$ of saponin solution was placed in a clean beaker in the instrument chamber. After temperature equilibrium was attained, a vertical plate of platinum-iridium, attached to a balance, was immersed in the solution and the force due to wetting was determined by the instrument. Surface tension of a series of concentrations of saponin was measured and the concentration at which an abrupt change in the surface tension took place was regarded as the cmc.

Hemolytic effects of ATS: Preparation of red blood cell (RBC) suspension: Approximately $10 \mathrm{ml}$ of blood was taken from a healthy volunteer into a heparinized tube and put in ice. The plasma and buffy coat were removed by centrifuging blood samples at $2200 \mathrm{~g}$ (Hermle Z 230A) for $10 \mathrm{~min}$ and the erythrocytes were washed three times with at least five times their volume of Mcllvaine's buffer, $\mathrm{pH}$ 7.0. The erythrocytes were adjusted to approximately $12 \%$ haematocrit by resuspending them in the same buffer to 3.33 times their original weight. The erythrocyte suspension was stored on ice at $4^{\circ} \mathrm{C}$ and was used within $48 \mathrm{~h}$ of collection.

Haemolysis experiments: $200 \mu \mathrm{l}$ of RBC suspension was incubated for 30 min with an equal volume of the saponin solution, prepared in Mcllvaine's buffer, at $37^{\circ} \mathrm{C}$. After incubation, the mixtures were spun in a microcentrifuge (Hettich 2415) at $3200 \mathrm{~g}$ for $15 \mathrm{~s}$ and $200 \mu \mathrm{l}$ of the resulting supernatant was added to $3 \mathrm{ml}$ Drabkin's reagent to assay for the amount of haemoglobin released. Positive controls consisted of $200 \mu \mathrm{l}$ samples taken from uncentrifuged mixtures of erythrocyte suspensions $(200 \mu \mathrm{l})$ and buffer $(200 \mu \mathrm{l})$, which were added to $3 \mathrm{ml}$ Drabkin's reagent to obtain complete hemolysis. A negative control was also included to assess the levels of spontaneous hemolysis; it comprised $200 \mu \mathrm{l}$ buffer mixed with $200 \mu \mathrm{l}$ erythrocyte suspension. The absorbance at $540 \mathrm{~nm}$ of all test and control samples was determined spectrophotometrically using a UV-visible spectrophotometer (Shimadzu 160-A, Japan) and the values, expressed as percentage hemolysis, were calculated by comparing the absorbance of test samples with that of positive control. Haemolysis caused by negative controls was always less than $1 \%$.

\section{In vivo animal studies}

Preparation of control and test solutions: All solutions were prepared freshly on the day of experiment and refrigerated until use. Control solutions were prepared by dissolving $40 \mathrm{mg}$ carboxymethylcellulose (CMC) in $2 \mathrm{ml}$ PBS, pH $7.0(1 \% \mathrm{w} / \mathrm{V}$ final concentration) by gentle heating and adding $2 \mathrm{ml}$ regular insulin $(100 \mathrm{IU} / \mathrm{ml})$ after it cooled. Test solutions were made by the addition of $40 \mathrm{mg}$ each of ATS, QTS and SC to $2 \mathrm{ml}$ of the cooled CMC solution and mixing with $2 \mathrm{ml}$ regular insulin to obtain $1 \% \mathrm{w} / \mathrm{v}$ enhancer concentration and $50 \mathrm{IU} / \mathrm{ml}$ of insulin in the final solution.

Animal experiments: Male Wistar rats weighing 240$300 \mathrm{gm}$ were bred in the animal house of the Department of Pharmacology, School of Pharmacy of Mashhad. The rats were treated surgically according to the method described earlier ${ }^{[11]}$ with slight modifications. After anesthesia with intraperitoneal injection of urethane $(1.3 \mathrm{~g} / \mathrm{kg})$, an incision was made at the neck of the rat to expose the trachea. A polyethylene tube was inserted about $1.5 \mathrm{~cm}$ into the trachea to maintain respiration during the experiment. Body temperature was fixed at $37 \pm 0.5^{\circ} \mathrm{C}$. The esophagus was also cannulated with another similar polyethylene tube, which was closed at the end with an adhesive agent and inserted toward the posterior nasal cavity. The nasopalatine was sealed with an adhesive agent to prevent drainage of the drug solution from the nasal cavity into the mouth. The left carotid and right external jugular veins were cannulated for blood sampling and fluid replacement, respectively.

Insulin absorption studies: Groups of five animals were used for the nasal administration of control and test solutions. The animals were manually restrained in a supine position while the solution was instilled into the nostril. Test solutions were always administered through the rat's right nostril and the nostril was then closed immediately with an adhesive agent.

At time points 0 and $5 \mathrm{~min}, 20 \mu \mathrm{l}$ of insulin solution containing 1 IU insulin was instilled into the rat's nostril. Thus, each rat received 2 IU of insulin. The mean blood glucose concentration of three samplings at 5 min intervals before drug administration was measured and taken as the basal blood glucose concentration.

Blood glucose concentration was determined using a glucometer (Sensorex, Metertech Inc, USA) with special glucometer strips (Apex Biotechnology Corp.) and the value was taken as an indicator of the systemic absorption of insulin via the nose. Blood samples were withdrawn from the jugular vein and 
replaced by the same volume of normal saline. Samples were taken at time points 10, 20, 30, 40, 55, 70, 100 and $130 \mathrm{~min}$ after drug administration and blood glucose concentrations were determined as described above. The blood glucose level was reported as a percentage of basal blood glucose concentration for each sample.

\section{Statistical analysis}

Analysis of data was done using the Minitab software. The data were expressed as mean values \pm SD and tested for significance by one-way analysis of variance (ANOVA) followed by the multiple comparison test of Tukey-Kramer. $P<0.05$ was regarded as indicating statistical significance.

\section{Results}

\section{HPLC analysis}

Figure 1 shows the HPLC fingerprint of the total saponin isolated from A. squarrosum.

Surface tension studies: According to the data obtained in this study, the average surface tension of pure water at room temperature $\left(21^{\circ} \mathrm{C}\right)$ was found to be $72.62 \pm 0.67 \mathrm{mN} / \mathrm{m}$. Critical micelle concentration (cmc) was taken from the region where the surface tension vs concentration curve reached a plateau and it was found to be 120,50 and $160 \mu \mathrm{g} / \mathrm{ml}$ for SLS, ATS and QTS, respectively [Figure 2].

Figure 1: HPLC fingerprint of ATS

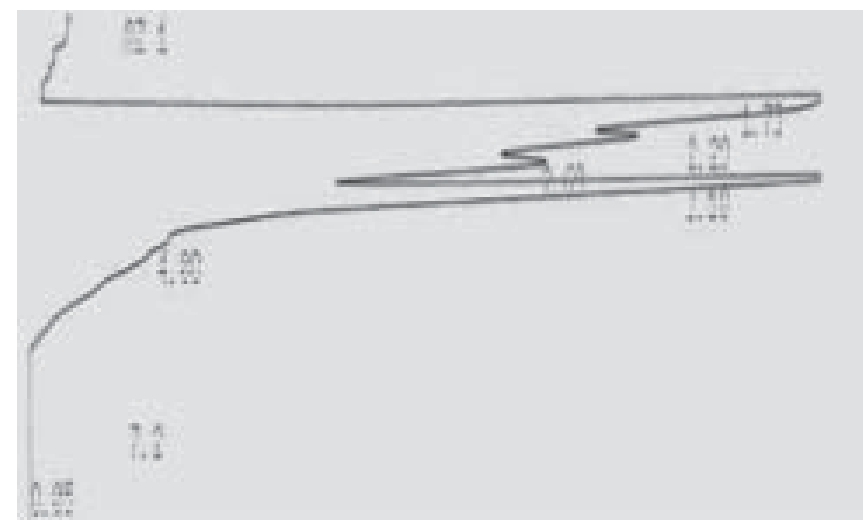

Figure 2: Surface tension changes with increasing enhancer concentration

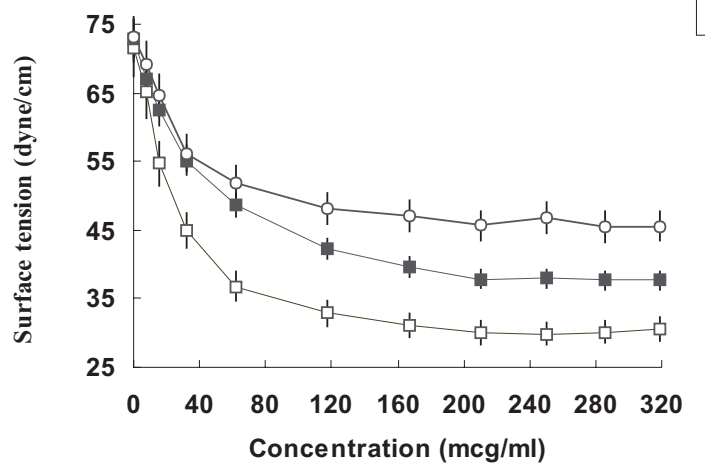

Hemolysis studies: Figure 3 shows the haemolysis vs concentration profiles for SLS, ATS and QTS. In general, the maximum hemolytic effect occurs at concentrations above cmc. There was a sharp increase in hemolysis with increasing concentrations of the three compounds. As Figure 3 indicates, among the compounds tested, SLS showed the maximum efficacy in terms of disruption of red blood cell membranes. The hemolysis profiles of ATS and QTS are almost the same and both of them caused complete hemolysis at a concentration of about $250 \mu \mathrm{g} / \mathrm{ml}$.

Nasal absorption studies

In this study, nasal insulin absorption in the presence of three absorption enhancers was investigated by determination of the decrease in blood glucose levels in rat. As Figure 4 shows, ATS at a concentration of $1 \% \mathrm{w} / \mathrm{v}$ decreased blood glucose significantly $(P<0.01$ or $P<0.001)$ as compared to the control at all time points after nasal administration of insulin except at the time point of $10 \mathrm{~min}$. Figure 4 also shows the effect of a $1 \% \mathrm{w} / \mathrm{v}$ concentration of both QTS and SC on nasal absorption

Figure 3: Plot of haemolytic effects on human red blood cells of SLS, ATS and QTS in buffer $\mathrm{pH} 7$ at $25^{\circ} \mathrm{C}$

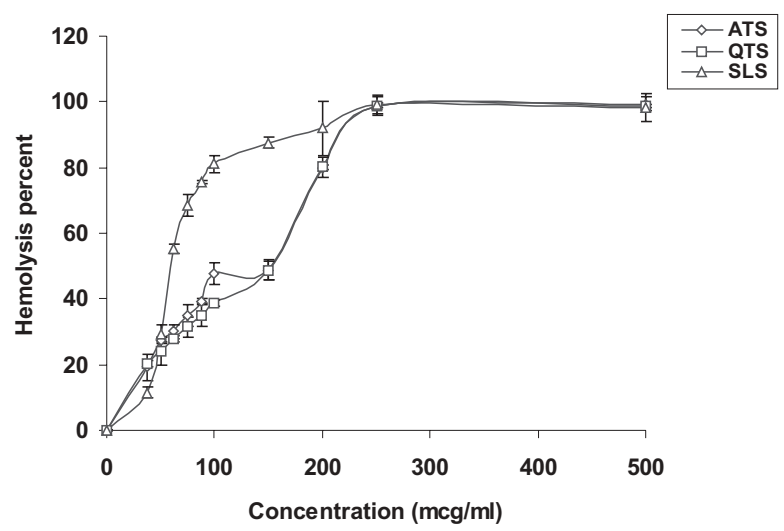

Figure 4: Mean blood glucose concentrations after intranasal administration of $2 \mathrm{IU}$ of regular insulin alone $(\bullet)$, with $1 \% \mathrm{w} / \mathrm{V}$ ATS $(\boldsymbol{\square})$, with $1 \% \mathrm{w} / \mathrm{v}$ QTS $(\bullet)$, with $1 \% \mathrm{w} / \mathrm{V} \mathrm{SC}(\boldsymbol{\Delta})$ in rat $(n=5)$. Each data point represents the mean \pm SD values of five experiments. ${ }^{*} P<0.01$ compared to control (insulin alone); ${ }^{* *} P<0.001$ compared to control (insulin alone)

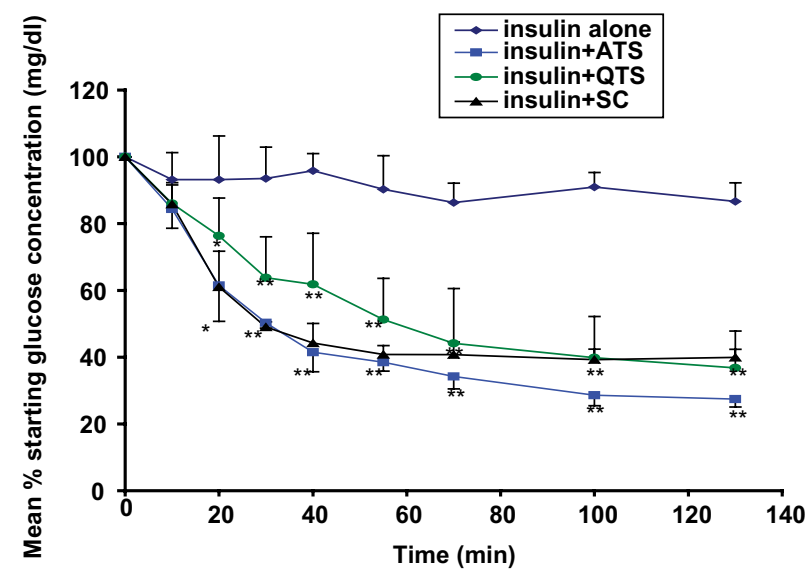


of insulin. It is evident that both compounds decreased blood glucose significantly as compared to the control. At $130 \mathrm{~min}$ post-instillation of insulin in the presence of the enhancers blood glucose was found to be $27.46 \%, 36.79 \%$ and $39.95 \%$ that of basal values for ATS, QTS and SC, respectively. Although the effect of ATS on blood glucose and insulin absorption was found to be more pronounced than that of the other two enhancers [Figure 4], the difference was not statistically significant $(P>0.05)$.

\section{Discussion}

Surface tension studies showed that ATS was able to lower the surface tension of water in a concentration-dependent manner. SLS, which is an ionic surfactant, induced a sharp decrease in surface tension. QTS was also shown to decrease the surface tension of water in a similar manner, though it was less effective than SLS. In a study carried out by Shuman and coworkers $^{[15]}$ on the micellar properties of Quillaja saponins, the cmc of saponins was reported as $130-510 \mu \mathrm{g} / \mathrm{ml}$, depending on the purity and source of the saponin. ${ }^{[15]}$ Our study showed the cmc of ATS as being around $80-120 \mu \mathrm{g} / \mathrm{ml}$, which is in logical agreement with the above results if we take into account the difference in the plant species and also the degree of purity of ATS as shown in the HPLC chromatogram. Saponins have the ability to rupture erythrocytes and this has led to the development of the hemolytic assays for detecting the presence of saponins in plant extracts. ${ }^{[16]}$ Pillion et al., found that saponins isolated from Quillaja saponaria bark hemolysed sheep red blood cells at fairly low concentrations. ${ }^{[13]}$ As the results of the present study show, the hemolysis profile of the ATS and QTS were almost identical and complete hemolysis was observed for both compounds at the concentration of $250 \mu \mathrm{g} / \mathrm{ml}$. Since this concentration is above the CMC of ATS, membrane disruption could be attributed to the formation of mixed micelles and extraction of membrane components by saponin micelles.

In vivo animal studies demonstrated that intranasal administration of solutions containing insulin with QTS, SC and ATS significantly $(P<0.05)$ reduced blood glucose compared to the basal values in rat. This indicates that the tested compounds possess an enhancing effect on intranasal absorption of insulin. The extent of the effect of these three enhancers was not found to be different statistically $(P>0.05)$. QTS and cholates are known absorption enhancers and have been studied by other researchers as well. Chandler et al., studied the effect of sodium taurodihydrofusidate (STDHF; a bile derivative), L- $\alpha$ lysophosphatidyl choline (LPC), polyoxyethylene-9-lauryl-ether (laureth 9) and diethylamine ethyl-dextran (DEAE-dextran) on nasal absorption of insulin in rat. ${ }^{[17]}$ They found that all these enhancers increased insulin absorption with their ranking order being as follows: Laureth $9>\mathrm{LPC}=\mathrm{STDHF}>\mathrm{DEAE}-$ dextran $\geq$ no enhancer. ${ }^{|17|}$ The effect of sodium deoxycholate (SDC) on intranasal absorption of insulin was studied and the results showed that when insulin $(0.5 \mathrm{IU} / \mathrm{kg})$ in saline $(\mathrm{pH}$ 7.4) was administered without any absorption enhancer, no change in blood glucose level and insulin concentration was observed; however, blood glucose reduced in 10-20 min when $1 \%$ SDC was added to the insulin solution. ${ }^{[18 \mid}$ The potency of bile salts in enhancing nasal absorption of insulin in human volunteers was ranked as deoxycholate $>$ chenodeoxycholate $>$ cholate $>$ ursodeoxycholate. ${ }^{|7|}$ It has been reported that bile salts such as cholate, glycocholate and taurocholate produce smaller effects than nonionic, anionic and nonionic ester type surfactants on both hemolytic activity and protein-releasing effect, though the absorption-enhancing effects were significant and almost the same as those of ether type surfactants, sodium lauryl sulfate and saponin. ${ }^{99}$ It was also found that bile salts such as sodium glycocholate (SGC) were less irritant to the nasal mucosa than polyoxyethylene 9-lauryl ether. ${ }^{[9]}$ In a study on oral insulin delivery, Hosny and coworkers showed that sodium cholate (SC) induced a decrease in the blood glucose level following its oral administration along with insulin to hyperglycemic rabbits. ${ }^{[19]}$ Plant saponins have been examined for their absorption-enhancing effects in a number of studies. Pillion et al., studied naturally occurring QTS and their derivatives for their ability to stimulate insulin delivery from nose and eye drops. ${ }^{[13 \mid}$ This group of researchers instilled 2 IU insulin in the presence of different concentrations of QTS and derivatives into the nose/eye of rat and assessed insulin absorption by the hypoglycemic response of the animal. ${ }^{13]}$ They found that all the tested saponins and derivatives showed an enhancing effect on insulin absorption and reduced blood glucose levels in rat, though there were differences in the extent of their effects. ${ }^{|13|}$ However, the enhancing effect of ATS on the absorption of insulin has not been reported in the literature.

In this research, all three solutions containing absorption enhancers significantly reduced blood glucose in rat as compared to the control solution at almost all time points postinsulin administration. ATS $(1 \% \mathrm{w} / \mathrm{v})$ reduced blood glucose to $84.3 \%( \pm 5.7 \%) 10 \mathrm{~min}$ after instillation, which was not significantly different from that of control $(P>0.05)$ [Figure 4]. From the time point 20 min onwards, however, the reduction in blood glucose was statistically different $(P<0.01)$ from that caused by control. At the time point of $130 \mathrm{~min}$ blood glucose was reduced to $27.4 \%( \pm 2.4 \%)$, which indicates a considerable effect of ATS on intranasal insulin absorption. The efficacy of ATS in promoting insulin absorption was found to be slightly greater than those of QTS and SC, but the differences were not significant at any of the time points $(P>0.05)$.

In conclusion, this study demonstrated that ATS extracted from the root of Acanthophyllum squarrosum was able to promote insulin absorption via the nasal route, with a promoting power equal to or slightly greater than (although not significant) that of two known enhancers. The mechanism of action whereby ATS and other saponins enhance the systemic absorption of insulin is not known clearly. Similarly, the precise mechanism of action of a variety of other enhancers, including bile salts and their derivatives, remain unidentified at present. Pillion et al. ascribed the enhancing effects of Quillaja saponins to the formation of mixed micelles with insulin that facilitates its transepithelial absorption. ${ }^{[13]}$ Since the concentration of ATS used in this study was above its cmc, the above mentioned mechanism could be attributed to ATS as well. However, the effect of saponins on tight junctions and the promotion of insulin absorption through the paracellular pathway might be another possible mechanism.

\section{Acknowledgment}

This research project has been supported financially by Grant No. NRCI 6640 of National Research Projects and was done with the support of the National Research Council of the Islamic Republic of Iran. 


\section{References}

1. Tyler VE, Brady LR, Robbers JE, editors. Pharmacognosy. 8th ed. Lea and Febiger: Philadelphia, USA; 1981.

2. Herlt AJ, Mander LN, Pongoh E, Rumampuk RJ, Tarigan P. Two major saponins from seeds of Barringtonia asiatica: Putative anti-feedants toward Epilachna sp. larvae. J Nat Prod 2002;65:115-20.

3. Hincheliffe M, Illum L. Intranasal insulin delivery and therapy. Adv Drug Deliv Rev 1999;35:199-234.

4. Illum L. Nasal drug delivery-possibilities, problems and solutions. J Control Release 2003;87:187-98.

5. Merkus FW, Verhoef JC, Romeijn SG, Schipper NG. Absorption enhancing effect of cyclodextrin on intranasally administered insulin in rats. Pharm Res 1991;8:588-92.

6. Merkus FW, Schipper NG, Verhoef JC. The influence of absorption enhancers on intranasal insulin absorption in normal and diabetic subjects. J Cont Rel 1996;41:69-75.

7. Hersey SJ, Jackson RT. Effect of bile salts on nasal permeability in-vitro. J Pharm Sci 1987;76:876-9.

8. Aungst BJ, Rogers NJ. Site dependence of absorption promoting actions of laureth-9, sodium salicylate, disodium EDTA and aprotinin on rectal, nasal and buccal insulin delivery. Pharm Res 1988;5:305-8.

9. Hirai S, Yashiki Y, Mima S. Effect of surfactants on the nasal absorption of insulin in rats. Int J Pharm 1981;9:165-72.

10. Illum L, Farraj NF, Critchley H, Johansen BR, Davis SS. Enhanced nasal absorption of insulin in rats using lysophosphatidylcholine. Int J Pharm 1989;57:49-54.
11. Aspden TJ, Illum L, Skaugrad Q. Chitosan as a nasal delivery system: Evaluation of insulin absorption enhancement and effect on nasal membrane integrity using rat models. Eur J Pharm Sci 1996;4:23-31.

12. Sinswat $P$, Tengamnuay $P$. Enhancing effect of chitosan on nasal absorption of salmon calcitonin in rats: Comparison with hydroxypropyl- and dimethyl-betacyclodextrins. Int J Pharm 2003;257:15-22.

13. Pillion DJ, Amsden JA, Kensil CR, Cchia JP. Structure-function relationship among Quillaja saponins serving as excipients for nasal and ocular delivery of insulin. J Pharm Sci 1996;85:518-24.

14. Lacaille-Dubois M, Hanquet B, Rustaiyan A, Wagners H. Squarroside A, a biologically active triterpene saponin from Acanthophyllum squarrusom. Phytochemistry 1993;34:489-95.

15. Shuman M, Dungan SR. Micellar properties of quillaja saponin. 2: Effect of solubilized cholesterol on solution properties. Coll Surf Biointerfaces 2000;17:11733.

16. Sprag SG, Light ME, van Staden J. Biological activities and distribution of plant saponins. J Ethnopharmacol 2004;94:219-43

17. Chandler SG, Illum L, Thomas NW. Nasal absorption in rats, II: Effect of enhancers on insulin absorption and nasal histology. Int J Pharm 1991;76:61-70.

18. Moses AC, Gordon GS, Carey MC, Flier JS. Insulin administered intranasally as an insulin-bile salt aerosol: Effectiveness and reproducibility in normal and diabetic subjects. Diabetes 1983;32:1040-7.

19. Hosny EA, Ghlzai NM, Elmazar MM. Promotion of oral insulin absorption in diabetic rabbits using $\mathrm{pH}$-dependent coated capsules containing sodium cholate. Pharm Acta Helv 1997;72:203-7. 